\title{
A GAS-JET SYSTEM FOR THE STUDY OF SHORT-LIVED, LIGHT FISSION PRODUCTS
}

\author{
K. RENGAN, * H. C. GRIFFIN** \\ *Department of Chemistry, Eastern Michigan University, Ypsilanti, MI., 48197, (USA) \\ **Department of Chemistry University of Michigan \\ Ann Arbor, MI., 48109 (USA)
}

(Received April 17, 1985)

\begin{abstract}
For the study of short-lived fission products, a gas jet system has been set up in a beam port of the Ford Nuclear Reactor at the University of Michigan. The system consists of a target chamber joined to three polyethylene tubes which serve as gas inlet, fission product outlet and an outlet for pressure monitoring. The target chamber is housed in a $7.6 \mathrm{~cm}$ (ID) aluminum tube supported inside a radial beam port. This tube can be withdrawn by $\sim 1 \mathrm{~m}$, allowing the target chamber to be positioned either close to or $\sim 1 \mathrm{~m}$ from the core. The aluminum tube is surrounded by water, which provides shielding and protects the target when not in use (at $\sim 1 \mathrm{~m}$ position). The target is $\sim 1 \mathrm{mg}$ of ${ }^{235} \mathrm{U}$, chemically plated on an aluminum planchett. The uranium is covered with $2.7 \mathrm{mg} \cdot \mathrm{cm}^{-2}$ of aluminum. The aluminum covering stops most of the heavy fission fragments; the light fission fragments pass through the foil and are thermalized in a gaseous mixture of nitrogen and ethylene. The transport time of fission products from the target chamber to the detector position was measured to be $970 \mathrm{msec}$. Preliminary experiments indicate that the transport time can be reduced further. The gas jet system is being utilized for the development of fast, gas-phase chemistry for the separation of bromine from fission products.
\end{abstract}

\section{Introduction}

Study of low-lying energy levels of nuclides far from stability provides important information for a complete understanding of nuclear structure. Such studies also provide data of fundamental significance to a wide variety of fields ranging from theories regarding the origin of elements to technological calculations on the control and safety of reactors. In the last decade much of the progress in low-energy nuclear science has consisted of explorations of nuclides far from stability.

Nuclear fission provides a rich source of neutron-rich nuclides. Several hundred nuclides belonging to about thirty different elements are formed in fission. Ideally, chemical and mass separation should be performed for studying short-lived nuclides formed in such a mixture. However such separations are not technically feasible for very short-lived nuclides. For noble gases and alkalies, mass separation techniques have been used extensively. ${ }^{1-4}$ Elements which are not accessible by mass-separator ion-sources have been studied by chemical separation techniques. ${ }^{5-7}$

The type of chemical separation technique used depends on the half-life of the nuclide. Classical chemical separation techniques like solvent extraction ${ }^{8,9}$ ion- 
exchange ${ }^{10,11}$ and volatilization ${ }^{12,13}$ were the techniques of choice for studying nuclides with half lives of a few minutes or longer. A number of these procedures have been adapted for automation and used for studying nuclides with half lives-in the range of seconds. ${ }^{7}$ HENRY et al. ${ }^{14}$ have used a highly automated hydride production technique to study arsenic isotopes with half-lives as short as 5 seconds. Automated solvent extraction was used by TITTEL et al. ${ }^{15}$ to study short-lived molybdenum isotopes. It has been shown that for studying species with half-lives less than a few seconds continuous systems of production and isolation are much more efficient than the automated "..batch" systems. ${ }^{16}$

For continuous production and isolation of short-lived fission products two major components are essential: (1) a method to continuously produce and deliver fission products in a short time (comparable with the half-life of the nuclide of interest) to a separation system and (2) a system capable of continuously separating the nuclides of interest and delivering them to a detector system. Gas jet systems have been used to transport reaction products continuously from an irradiation position in accelerators to a detector for measurement. ${ }^{17}$ The gas jet system has been adapted for continuous delivery of fission products from a target chamber in a nuclear reactor to a separation system where chemical or mass separation can be carried out. ${ }^{18,19}$ Different kinds of aerosols have been used in the gas jet to carry the fission products; the common ones are ethylene, ${ }^{19,20}$ potassium chloride ${ }^{21}$ and sodium chloride. ${ }^{22}$

Two different approaches have been used for achieving continuous chemical separation of the product of interest. Conventional solvent extraction procedures have been coupled with high speed centrifuges for rapid phase separation..$^{23} \mathrm{~A}$ gas jet system and gas phase separations have been used for elements like selenium and tellurium, ${ }^{24-28}$ and the feasibility of a gas-phase procedure for studying short-lived bromine isotopes has also been shown. ${ }^{29}$

A covered-target, gas jet system has been set up in a beam port of the Ford Nuclear Reactor (FNR) at the University of Michigan. This paper describes the characteristics of that gas jet system. The transportation time measurement for fission products in the gas jet using stopped-flow techniques has been described. In addition, the results of the preliminary experiments performed using the gas jet to separate short-lived bromine isotopes are reported.

\section{Gas jet setup}

The FNR is a swimming pool type reactor. The reactor operates at a power level of $2 \mathrm{MW}$ and has several beam ports available for experimenters. The gas jet has been set up in a $15 \mathrm{~cm}$ ID beam port. A $8.75 \mathrm{~cm}$ OD aluminum tube, closed at the core side and open at the other end, is inserted into the beam port. This aluminum tube houses the target chamber and the tubes through which gas mixtures and fission products flow. The space outside the aluminum tube in the beam port is filled with water, which provides the necessary biological shielding. 
The target chamber is located inside the aluminum tube, near the closed end. A series of modular ( $60 \mathrm{~cm}$ or $30 \mathrm{~cm}$ in length) concrete cylinders, with spiral conduits, are inserted behind the target chamber. The total length of the cylinders is about $180 \mathrm{~cm}$. The concrete completes the biological shielding. Figure 1A shows a sketch of the gas jet system.

A sketch of the target chamber is shown in Fig. 1c. The target is $\sim 1 \mathrm{mg}$ of ${ }^{235} \mathrm{U}$, chemically plated on an aluminum planchette. The target is covered with several thin aluminum foils, with a total thickness of $2.75 \mathrm{mg} \cdot \mathrm{cm}^{-2}$. The aluminum foils stop essentially all of the heavy fragments while allowing a good fraction of the light fragments to pass through. ZENDEL et al. ${ }^{30}$ have shown that this arrangement provides an enhancement factor of at least 100 for light fission fragments. Three tubes pass through the conduits in the concrete cylinders and are connected to the target chamber. One is connected to the gas inlet and a second one to the fission product outlet of the target chamber; the third tube is used for monitoring the pressure of the target chamber.

Provision had to be made to reduce the neutron irradiation of the target chamber when the gas jet is not in operation. The aluminum tube is mounted in such a way that it can be withdrawn by $\sim 1 \mathrm{~m}$ when the gas jet is not in operation (non-irradiation position). Since the aluminum tube is surrounded by water, the target chamber is shielded by $\sim 1 \mathrm{~m}$ water in the non-irradiation position. A sketch of the gas jet in the non-irradiation position is shown in Fig. 1 b.
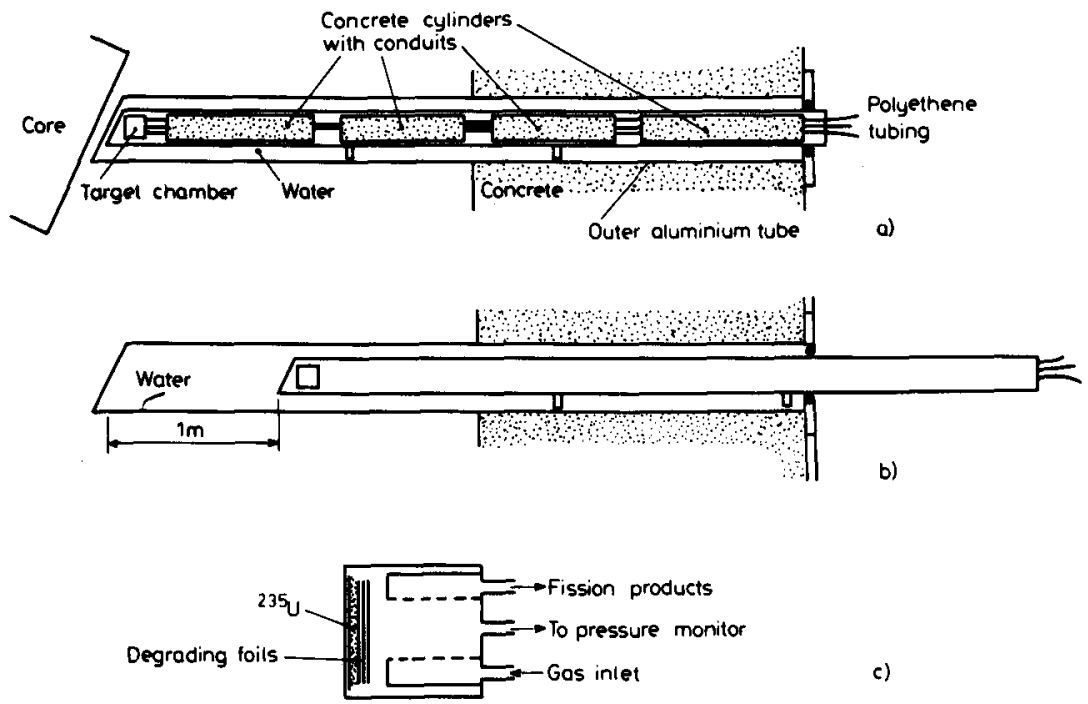

c)

Fig. 1. Schematic of the target chamber and its location relative to the reactor core; a - sketch of gas-jet system in irradiation position, $b$ - sketch of gas-jet system in non-irradiation position c - target chamber 


\section{Experimental}

\section{Gas-jet operation}

In the gas-jet system a mixture of nitrogen and ethylene was used as the gas mixture to carry the fission products. Non-volatile fission products carried by ethylene clusters were collected in a quartz wool trap set up in front of a $\mathrm{Ge}(\mathrm{Li})$ detector. The gamma-ray spectra of mixed fission products collected on the trap were recorded using a Canberra series 80 multichannel analyzer.

The gases carrying volatile fission products flowed through the quartz wool trap and was then passed through a reservoir containing activated charcoal, The gases were then passed through a charcoal filter, pump and then exhausted. As a safety check the charcoal filter was monitored for longer-lived iodine gamma rays.

\section{Transport time}

The transport time of the non-volatile, mixed fission products from the target chamber to the detector position was measured using the stopped-flow technique developed by RENGAN et al. ${ }^{31,32}$ The arrangement used in the measurement is shown in Fig. 2. The gas mixture passed through an electrically operated three-way valve to the target chamber.

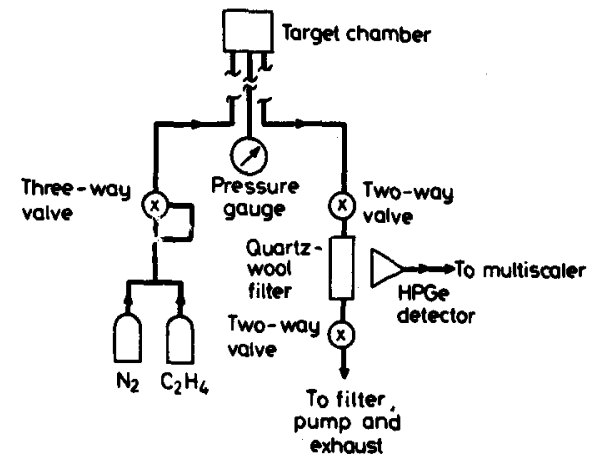

Fig. 2. Schematic of the experimental set up for transport time measurements

The connection was made in such a way that the gas mixture flowed to the target chamber when power was applied to the valve. The gas mixture from the target chamber carrying the fission products was passed through an electrically operated two-way valve to a quartz wool trap. The trap retained most of the non-volatile fission products carried by the ethylene clusters. The gas flowing out of the trap passed through another electrically operated two-way valve to the pump and exhaust. The quartz wool trap and the two two-way electrically operated valves were located close to each other. The power for all the three valves were applied by the operation of a single switch; the switch also initiated the multiscaling. 


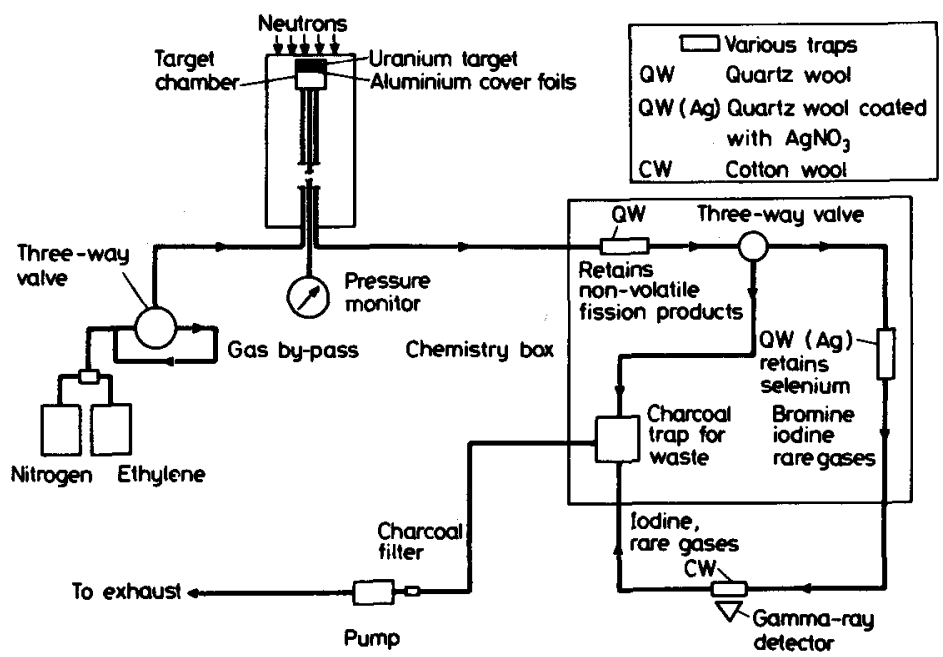

Fig. 3. Schematic diagram of the set up used for the separation of bromine from fission products

\section{Separation of bromine}

The setup used for bromine separation is shown in Fig. 3. The gas mixture carrying the fission products was passed through a quartz wool filter and then through a filter of quartz wool coated with $\mathrm{AgNO}_{3}$. The gas was then passed through a trap of moist cotton wool in front of a $\mathrm{Ge}(\mathrm{Li})$ detector. The gamma-ray spectra of the nuclides collecting in the cotton wool trap was recorded using a Canberra series 80 multichannel analyzer.

\section{Results and discussion}

\section{Fission product delivery}

The gamma-ray spectra of the quartz wool trap obtained on-line using the gas jet showed the presence of mostly short-lived, light mass fission products. The level of fission product activity was quite satisfactory. Figure 4 shows a portion of the gamma-ray spectra of mixed fission products collected in the quartz wool trap, after a 22-hour decay. The absence of gamma-ray peaks at $228 \mathrm{keV}$ due to 78.2 -hour ${ }^{132} \mathrm{Te}$ and at $293 \mathrm{keV}$ due to 33.0 -hour ${ }^{143} \mathrm{Ce}$ indicate that heavy fission fragments were retained by the aluminum foil covering the uranium target; mostly the light fission fragments penetrated the foil and were carried by the gas stream. The predominant peaks seen in the portion of the spectra shown here are due to ${ }^{91} \mathrm{Sr},{ }^{97} \mathrm{Nb},{ }^{97} \mathrm{~m}_{\mathrm{Nb}}$ and ${ }^{99 \mathrm{~m}} \mathrm{Tc}$, all light fission products. The gamma-ray spectra of mixed fission products obtained by ZENDEL $^{33}$ at the Gutenberg University gas jet using an uranium target without cover foil under comparable conditions (after a 22-h decay) showed the $228 \mathrm{keV}^{132} \mathrm{Te}$ and the $293 \mathrm{keV}{ }^{143} \mathrm{Ce}$ gamma-rays as prominent spectra. The spectra obtained for mixed fission products with this gas jet system compares favorably with that obtained by ZENDEL et al. ${ }^{30}$ 


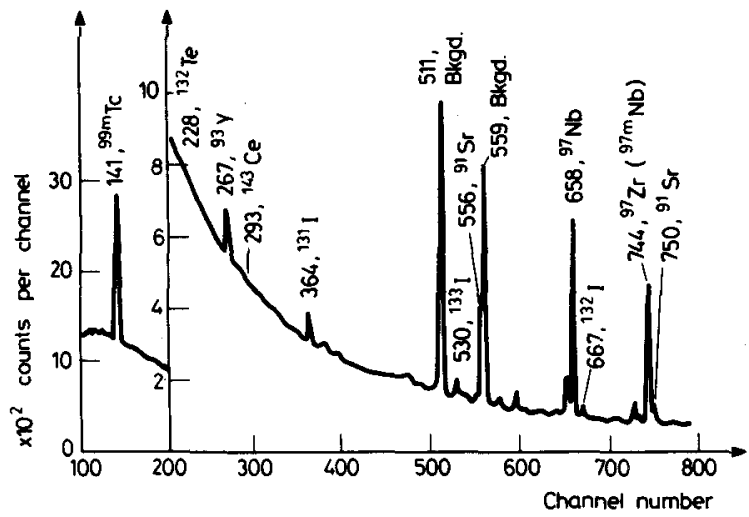

Fig. 4. Portion of the gamma ray spectra obtained with the uranium target covered with aluminum foil. Gamma ray energy given in $\mathrm{keV}$

Several safety tests were carried out with the gas jet system. The charcoal reservoir retains essentially all the radioactive material. ${ }^{131} \mathrm{I}$ activity was not detected in the charcoal filter in any of the safety tests or after any of the actual experiments.

\section{Transport time}

The target chamber has a volume of $2.0 \mathrm{~cm}^{3}$. The fission products generated in the target chamber were transported by the gas stream through $0.24 \mathrm{~cm}$ ID tubing over a distance of $6 \mathrm{~m}$ to the trap in front of the detector. Figure 5 shows the result of a typical experiment performed to measure the transport time. A gas flow rate of $0.64 l \cdot \mathrm{min}^{-1}$ (STP) was used for this experime ${ }_{i t}$. A transport time of $0.97 \mathrm{~s}$ was obtained. Preliminary experiments indicate that the transport time can be reduced to $0.6 \mathrm{~s}$ if a tube of $0.20 \mathrm{~cm}$ ID is used to carry the fission products. It is expected that with this gas jet system nuclides with half-lives around $500 \mathrm{~ms}$ can be studied with ease if appropriate gas phase chemistry could be developed.

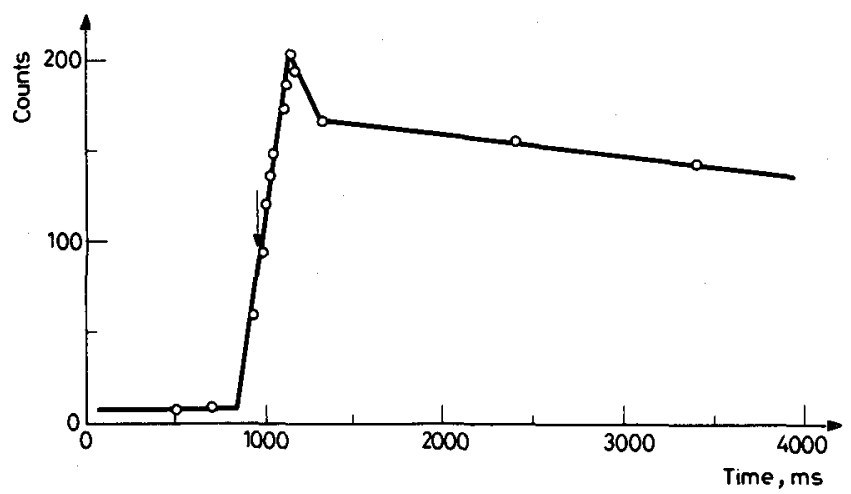

Fig. 5. Measurement of transport time of mixed fission products in the Ford Nuclear Reactor gas jet using stopped-flow technique; nylon tube $0.24 \mathrm{~cm} \mathrm{ID}$, mid-point of rise $970 \mathrm{~ms}$ 


\section{Bromine separation}

As a first step towards the study of short-lived bromine isotopes, a gas-phase separation of bromine from fission products is being developed. A nitrogen-ethylene gas mixture was used in the gas jet in several tests. The ethylene clusters physically carry the non-volatile fission products; elements like selenium, bromine and iodine form volatile products with ethylene or with radicals generated from ethylene. The first quartz wool filter retains all the non-volatile fission products. Selenium is retained by the filter containing quartz wool coated with $\mathrm{AgNO}_{3}$. The volatile compounds of bromine and iodine along with krypton and xenon flowed through. An activated charcoal trap was found to retain both bromine and iodine. A variety of other traps were tried for selective retention of bromine. Cotton wool wetted with water was found to give good separation from iodine. Figure 6 shows a portion of the gamma-ray spectra obtained with charcoal and cotton wool traps. Comparing the relative sizes of the $775-\mathrm{keV}$ peak of $16-\mathrm{s}{ }^{88} \mathrm{Br}$ with the $601-\mathrm{keV}$ peak of $24-\mathrm{s}^{137} \mathrm{I}$ and the $382 \mathrm{keV}$ peak of $45-\mathrm{s}{ }^{136 \mathrm{~m}_{\mathrm{I}}}$ in the two spectra shows the improvement obtained in the separation of bromine from iodine in the cotton wool trap; the iodine contamination was reduced by a factor of at least four. Further experiments are in progress to reduce the iodine contamination.
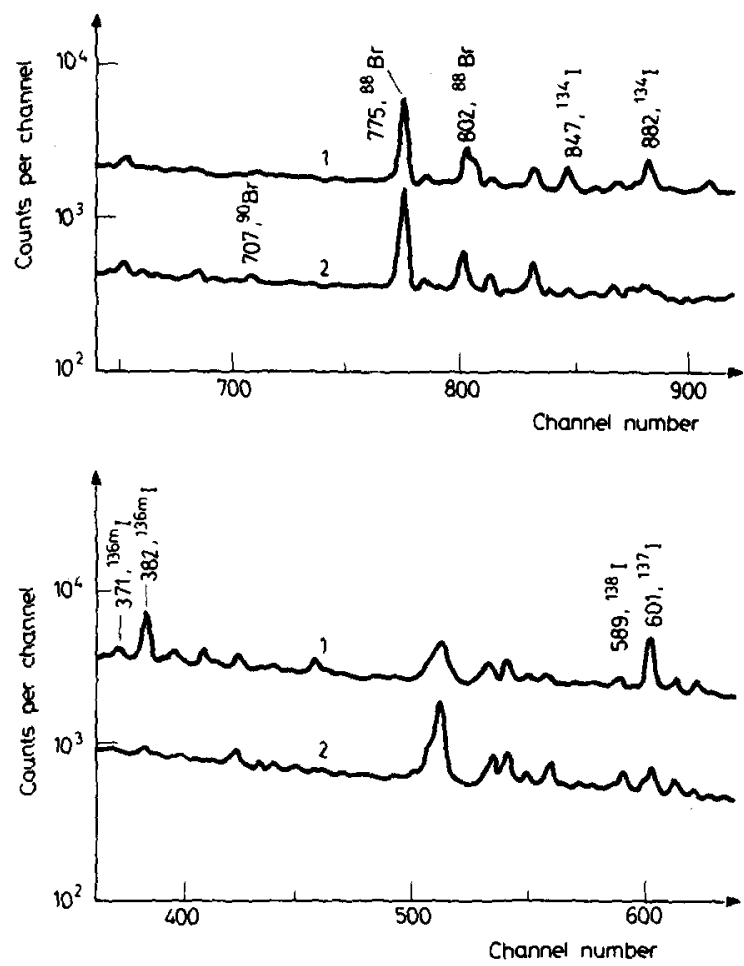

Fig. 6. Portion of the gamma ray spectra obtained for bromine with two different traps: curve 1 charcoal trap, curve 2 - cottonwool trap 
The support provided to K. RENGAN by Eastern Michigan University through Faculty Research Fellowships is gratefully acknowledged. The research was also supported in part by DOE cost sharing grant DE-FG02-80 ER 10724. The authors wish to thank Ford Nuclear Reactor personnel for their help.

\section{References}

1. R. KLAPISCH, Ann. Rev. Nucl. Sci., 19 (1969) 33.

2. R. KLAPISCH, In: Nuclear Spectroscopy and Reactions, part A, J. CERNY (Ed.), Academic Press, New York, 1974, p. 273.

3. P. G. HANSEN, Ann. Rev. Nucl. Part. Sci., 29 (1979) 69.

4. B. FOGELBERG, in: Nuclear Spectroscopy of Fission Products, T. von EGIDY (Ed.), The Institute of Physics, London, 1980, p. 27.

5. N. TRAUTMANN, G. HERRMANN, J. Radioanal. Chem., 32 (1976) 533.

6. R. A. MEYER, E. A. HENRY, in: Nuclear Spectroscopy of Fission Products, T. von EGIDY (Ed.). The Institute of Physics, London, 1980, p. 59.

7. G. HERRMANN, N. TRAUTMANN, Ann. Rev. Nucl. Part. Sci., 32 (1982) 117.

8. K. RENGAN, H. C. GRIFFIN, Radiochem. Radioanal. Lett., 24 (1978) 1.

9. K. RENGAN, H. C. GRIFFIN, Radiochem. Radioanal. Lett., 29 (1977) 253.

10. G. KLEIN, N. KAFFRELL,N.TRAUTMANN,G.HERRMANN, Inorg. Nucl. Chem. Lett., 11 (1975) 511.

11. J. D. BAKER, R. J. GEHRKE, R. C. GREENWOOD, D. H. MEIKRANTZ, J. Radioanal. Chem., 74 (1982) 117

12. J. V. KRATZ, H. FRANZ, G. HERRMANN, J. Inorg. Nucl. Chem., 35 (1973) 1407.

13. D. R. SLAUGHTER, F. M. NUH, S. G. PRUSSIN, J. Inorg. Nucl. Chem., 38 (1976) 1753.

14. E. A. HENRY, O. G. LIEN III, R. A. MEYER, Proc. $4^{\text {th }}$ Intern. Conf. on Nuclei Far From Stability, Helsingor, 1981, CERN Report No. 81-09, p. 334.

15. G. TITTEL, N. KAFFrELl, N. TRAUTMANN, G. HERRMANN, J. Inorg. Nucl. Chem., 39 (1977) 2115.

16. O. G. LIEN III, P. C. STEVENSON, E. A. HENRY, R. P. YAFFE, R. A. MEYER, Nucl. Instr. Methods, 185 (1981) 351.

17. R. D. MACFARLANE, Wm. C. McHARRIS, in: Nuclear Spectroscopy and Reactions, Part A, J. CERNY (Ed.), Academic Press, New York, 1974, p. 243.

18. R. E. CHRIEN, M. L. SHELTS, V. MANZELLA, R. L. GILL, F. K. WOHN, J. C. HILL, in: Nuclear Spectroscopy of Fission Products, T. von EGIDY (Ed.), The Institute of Physics, 1980, p. 44.

19. N. TRAUTMANN, P. O. ARONSSON, T. BJORNSTAD, N. KAFFRELL, E. KVALE, M. SKARSTAD, G. SKARNEMARK, Inorg. Nucl. Chem. Lett., 11 (1975) 729.

20. K. RENGAN, J. LIN, T. N. MASSEY, M. ZENDEL, R. A. MEYER, Radiochem. Radioanal. Lett., 50 (1982) 385.

21. E. STENDER, N. TRAUTMANN, G. HERRMANN, Radiochem. Radioanal.. Lett., 42 (1980) 291.

22. J. D. BAKER, R. J. GEHRKE, R. C. GREENWOOD, D. H. MEIKRANTZ, J. Radioanal. Chem., 74 (1982) 117.

23. G. SKARNEMARK, P. O. ARONSSON, K. BRODEN, J. RYDBERG, J. BJORNSTAD, N. KAFFRELL, E. STENDER, N. TRAUTMANN, Nucl. Instr. Methods, 171 (1980) 323.

24. R. J. SILVA, N. TRAUTMANN, M. ZENDEL, P. F. DITTNER, E. STENDER, H. AHRENS, Nucl. Instr. Methods, 147 (1977) 371.

25. M. ZENDEL, E. STENDER, N. TRAUTMANN, G. HERRMANN, Nucl. Instr. Methods, 153 (1978) 149. 
26. U. HICKMANN, N. GREULICH, N. TRAUTMANN, H. GAGGELER, H. GAGGELER-KOCH, B. EICHLER, Nucl. Instr. Methods, 174 (1980) 507.

27. K. RENGAN, J. LIN, T. N. MASSEY, M. ZENDEL, R. A. MEYER, Radiochem. Radioanal. Lett. 50 (1982) 385.

28. K. RENGAN, J. LIN, M. ZENDEL, R. A. MEYER, Nucl. Instr. Methods, 197 (1982) 427.

29. K. RENGAN, J. LIN, R. A. MEYER, Radiochem. Radioanal. Lett., 50 (1982) 393.

30. M. ZENDEL, K. RENGAN, T. N. MASSEY, S. G. PRUSSIN, R. A. MEYER, Submitted to Nucl. Instr. Methods.

31. K. RENGAN, J. LIN, T. LIM, J. HARRELL, R. A. MEYER, to be published.

32. K. RENGAN, H. C. GRIFFIN, J. LIN, T. LIM, J. HARRELL, R. A. ME YER, Bull. Amer. Phys. Soc. 29 (1984) 1044.

33. M. ZENDEL, Ph. D. Thesis, Johannes Gutenberg Universitat, Mainz, Federal Republic of Germany, 1978. 